\title{
Prednisone raw material characterization and formulation development
}

\author{
Leonardo Henrique Toehwé1,2, Livia Deris Prado ${ }^{3}$, Helvécio Vinícius Antunes Rocha ${ }^{2,3, *}$
}

\begin{abstract}
${ }^{1}$ Laboratório Químico-Farmacêutico da Aeronáutica, Rio de Janeiro, Brasil, ${ }^{2}$ Mestrado Profissional em Gestão, Pesquisa e Desenvolvimento na Indústria Farmacêutica, Farmanguinhos/Fiocruz, Rio de Janeiro, Brasil, ${ }^{3}$ Laboratório de Sistemas Farmacêuticos Avançados, Farmanguinhos/Fiocruz, Rio de Janeiro, Brasil
\end{abstract}

\begin{abstract}
Solid dosage forms for oral use, particularly tablets, are the most highly used dosage forms in therapy because they are easily administered, have high productivity and relatively low cost and provide a more stable drug to form a semi-solid net. Numerous parameters influence the quality of the final dosage form. In this study, the dissolution profile of 20-mg prednisone tablets bioequivalent to the reference product and three test formulations were evaluated using stability testing. During the study, prednisone tablets and the active pharmaceutical ingredient (API) prednisone from two different manufacturers were characterized with respect to their physical and physicochemical properties. The results showed that the dissolution profiles of the test batches and the reference product did not retain pharmaceutical equivalence throughout all the stability study. Notably, both samples of API prednisone were of the same crystal form, and any phase transition that occurred during the study could not be attributed to dissolution variation during stability.
\end{abstract}

Keywords: Prednisone/tablets/dissolution. Solubility. Formulation. Stability

\section{INTRODUCTION}

Prednisone is a glucocorticoid that is extensively used in clinical practice (Romanholi, Salgado, 2007). Its therapeutic use is recommended for a variety of acute and chronic diseases, such as arthritis, hepatitis, allergic diseases, asthma, leprosy, and numerous other autoimmune and inflammatory diseases (Kaiser, Kley, 2002).

In Brazil, there are several industries commercialising prednisone in the form of oral immediate release tablets. Currently, Meticorten ${ }^{\circledR}$ is the reference product for these formulations at concentrations of 5, 20 and $50 \mathrm{mg}$ (Anvisa, 2013).

Prednisone has the molecular formula $\mathrm{C}_{21} \mathrm{H}_{25} \mathrm{O}_{5}$ and a molar mass of $358.43 \mathrm{~g} / \mathrm{mol}$ (Farmacopeia Brasileira, 2010). It is an odourless white or almost white powder that melts at $233{ }^{\circ} \mathrm{C}$ with decomposition and may exhibit polymorphism. At room temperature, this drug is poorly soluble in methanol, ethanol, chloroform and dioxane, with

\footnotetext{
*Correspondence: H. V. A. Rocha. Laboratório de Sistemas Farmacêuticos Avançados, Farmanguinhos/Fiocruz. Av. Comandante Guaranys, 447 - Jacarepaguá-22775-903 - Rio de Janeiro - RJ - Brasil. E-mail: helvecio.far@gmail.com
}

low solubility in water (Farmacopeia Brasileira, 2010). Prednisone is a neutral molecule, and its $\mathrm{pK}_{\mathrm{a}}$ values are not reported in the literature. Its solubility in water is $0.133 \mathrm{mg} /$ $\mathrm{mL}$ at $25^{\circ} \mathrm{C}$, and three values for the partition coefficient $(\log \mathrm{P})$ are reported in the literature: $1.46,1.47$ and 1.6 (Vogt et al., 2007; Passion, Gouveia, Morais, 2012).

Commercially active pharmaceutical ingredient (API) prednisone is an anhydrous, monohydrate or prednisone acetate salt. However, only the anhydrous and monohydrate forms are referenced in the Brazilian, European and United States Pharmacopoeia (European Pharmacopoeia, 2010; Farmacopeia Brasileira, 2010; USP, 2012).

According to parameters adopted by the International Pharmaceutical Federation (FIP), prednisone is classified as a class I drug of the Biopharmaceutical Classification System (BCS) and is highly soluble and permeable (Storpirtis et al., 2009). However, Vogt et al. (2007) argued in a review study that in the absence of conclusive data on permeability, absorption and solubility under the conditions recommended by the BCS, this drug does not have a classification defined in relation to the BCS.

Full characterization of the drug is an essential step for a formulation development study given that variations 
in characteristics, such as crystal structure, particle size, and fluidity, can significantly impact on bioavailability parameters, processability and stability (Fung, Ng, 2003; Iacocca, Burcham, Hilden, 2010).

Another issue that is rarely evaluated is related to the monitoring of the dissolution properties of formulations during stability. Although there is a regulatory prerogative requiring the completion of the dissolution test for the stability study, there is no requirement for an analysis of the dissolution profile. Few authors have demonstrated the manner in which it makes a difference (Ochi et al., 2016; Payghan et al., 2012; Vidal et al., 2010).

The objective of the present study was to characterize the active pharmaceutical ingredient (API) prednisone and the formulation of a solid dosage form (tablet) for registration as a generic medicine and to evaluate the dissolution stability of this formulation.

\section{MATERIAL AND METHODS}

\section{Material}

The reference drug product was Meticorten ${ }^{\circledR}$ tablets $20 \mathrm{mg}$ (from Schering-Plough laboratory batch R023) produced in September 2010 and valid for two years. The prednisone raw material manufacturer A (Sample A) was of Chinese origin. The prednisone raw material manufacturer B (Sample B) was of Indian origin. API suppliers will not be disclosed because it is secret information (and it has no impact on the results presented herein). The excipients were corn starch (Quimica BPAR), croscarmellose sodium (Blanver), magnesium stearate (Magnesia), sodium starch glycolate (Amishi Drugs and Chemicals Ltd), lactose monohydrate (DFE Pharma), sodium lauryl sulfate (Stephan Philippines Inc.), mannitol (Shandong Tianli Pharmaceutical Co.), polyvinylpyrrolidone K30 (Nanhang Industrial Co.), and magnesium silicate (Talmag Pharma-S).

\section{METHODS}

\section{Raw material characterization}

\section{Differential scanning calorimetry}

Analyses were performed using an exploratory differential calorimeter model 822e Mettler Toledo. Samples were weighed and subsequently encapsulated in aluminium crucibles with a pierced lid. The DSC curves were obtained at temperatures ranging from 25 to $300^{\circ} \mathrm{C}$ using nitrogen at a flow rate of $80 \mathrm{~mL} / \mathrm{min}$ as the purge gas. Measurements were performed at the heating rates of 2.5, 5 and $10^{\circ} \mathrm{C} / \mathrm{min}$.

\section{Thermogravimetric analysis (TGA)}

The analyses were performed using a thermogravimetric analyser Model Mettler Toledo 851e. Samples of approximately $3.5 \mathrm{mg}$ were weighed and encapsulated in open aluminium pans. The TGA curves were obtained at a heating rate of $10{ }^{\circ} \mathrm{C} / \mathrm{min}$ in the temperature range from 30 to $450{ }^{\circ} \mathrm{C}$ using nitrogen at a flow rate of $80 \mathrm{~mL} / \mathrm{min}$ as the purge gas.

\section{Powder X-ray diffraction}

The X-ray diffractometer was operated with a potential difference across the tube of $30 \mathrm{kV}$ and 15 $\mathrm{mA}$. The measurements were performed in the range from 5 to $40^{\circ} 2 \theta$ with a goniometer speed of $0.05 \%$ sec. The radiation used was $\mathrm{CuK} \alpha(\lambda=1.5418 \AA)$. The experimental diffraction patterns were compared with a simulated diffraction pattern obtained from the Mercury software (Macrae et al., 2008), which was prepared using the deposited structure at the Cambridge Crystallographic Data Structure Database (CSD) (Allen, 2002).

\section{Fourier transform infrared spectroscopy}

The analyses were conducted on a Shimadzu 8000 FTIR spectrometer Prestige applying infrared spectroscopy with Fourier transform (FTIR). Approximately $3 \mathrm{mg}$ of each sample was weighed and mixed with previously dried potassium bromide at $105^{\circ} \mathrm{C}$ for 3 hours at a ratio of $10 \%$. Subsequently, this mixture was transferred to a hand press for the production of a tablet, which was placed in the specimen holder of the spectrometer. The same procedure was performed for the chemical reference substances (SQR) of the USP and Brazilian Pharmacopoeia. The spectra were recorded at $4000-400 \mathrm{~cm}^{-1}$.

\section{Intrinsic dissolution}

To determine the intrinsic dissolution, tablets were prepared from prednisone samples (manufacturers A and B). The samples were subjected to different levels of compressive forces. Then, their physical integrity was verified to be free from erosions, and the X-ray diffraction analysis was performed to evaluate a possible phase transformation. The pressure selected for the experiment was 1200 psi because the inserts exhibited no erosion and the drug showed no phase transition under this condition. Therefore, three tablets were obtained (one from each sample) containing approximately $120 \mathrm{mg}$.

Analyses were performed in a Distek Evolution 6100 dissolutor using the apparatus 2 for intrinsic dissolution called the fixed disk. The fixed disc assembly containing the inserts was deposited using forceps in a flat-bottom vessel containing $900 \mathrm{~mL}$ of water with $1.2 \%$ 
sodium lauryl sulfate (w/v). During the experiment, 10$\mathrm{mL}$ aliquots were collected without medium replacement at $5,10,15,20,30,45$ and 60 minutes. The parameters related to temperature and the rotational rate at which the analysis was conducted were $37 \pm 0.5^{\circ} \mathrm{C}$ and $150 \mathrm{rpm}$, respectively. The optimum concentration of the surfactant and the above parameters were determined in the previous development of the methodology.

The analyses were performed in triplicate, and the amount of active drug released was obtained by reading the absorbance in a UV spectrophotometer at a wavelength of $242 \mathrm{~nm}$. The results are expressed as intrinsic dissolution rate (IDR) and used for the construction of a graphic of the amount dissolved per area $\left(\mathrm{mg} . \mathrm{cm}^{-2}\right)$ versus time (minutes).

\section{Powder dissolution}

To determine powder dissolution behaviour by dispersion, $20 \mathrm{mg}$ of each sample (A and $\mathrm{B}$ ) was added to the dissolution vessel containing $900 \mathrm{~mL}$ of purified water. The analysis was performed in triplicate with the same parameters used for the dissolution test for prednisone tablets described in the Brazilian Pharmacopoeia (Farmacopeia Brasileira, 2010) (temperature of $37 \pm 0.5$ ${ }^{\circ} \mathrm{C}$ and stirring rate of $50 \mathrm{rpm}$ ), except that the collection times were 5, 10, 15, 20, 25 and 30 minutes. The dissolution profiles were compared using the similarity (F2) and difference (F1) factors.

\section{Scanning electron microscopy}

Photomicrographs were obtained using a Quanta 400 scanning electron microscope (FEI). API samples A and $\mathrm{B}$ were adhered to a piece of double-sided adhesive tape supported on a carbon support. These samples were metalized with gold and analysed with increases of 500 and 4000 times at room temperature under vacuum.

\section{Solubility}

To determine the solubility of the samples (A and B), an excess of powder was added to the dissolution vessels containing $500 \mathrm{~mL}$ of the following three different media: hydrochloric acid buffer $\mathrm{pH} 1.2$, phosphate buffer $\mathrm{pH} 6.8$ and distilled water $\mathrm{pH}$ 5.5. The vessels with solutions were placed in an ultrasound for 15 minutes $\left(37^{\circ} \mathrm{C}\right)$ and then transported to the dissolutor apparatus under a rotation rate of $100 \mathrm{rpm}$ and a temperature of $37 \pm 0.5^{\circ} \mathrm{C}$ for 24 hours. After this period, a $20-\mathrm{mL}$ aliquot was withdrawn from each vessel, and the suspensions were filtered through a $0.45-\mu \mathrm{m}$ membrane, diluted and then analysed by UV-Vis spectrophotometry at a wavelength of $242 \mathrm{~nm}$ (Okumu, Dimaso, Löbenberg, 2009; Wei, Löbernberg, 2006). Each experiment was performed in triplicate, and the $\mathrm{pH}$ of each sample was monitored during the experiment.

\section{Evaluation of the API according to pharmacopoeic criteria}

The assay for prednisone samples A and B was performed using ultraviolet absorption spectrophotometry according to the method (A) described in the Brazilian Pharmacopoeia $5^{\text {th }}$ edition (Farmacopeia Brasileira, 2010).

\section{Formulation}

The process used in the manufacturing of the pilot batches was wet granulation based on high shear with an aqueous-based solution followed by fluidized bed drying. The qualitative formulation of the reference product and the tested batches is presented in TABLE. Three batches were produced: P0020020910, MEST01 and MEST02. All of the batches followed the same manufacturing process. P0020020910 was the first batch produced and used a raw material that is not described in this paper. This batch was used in the bioequivalence study. Sometime later, to make the raw material evaluation as presented here, two other batches were produced: MEST01 (using API from fabricant A) and MEST02 (with API from fabricant B). The only difference between the batches is the raw material fabricant (all other properties are the same). P0020020910 was used in this study as an internal standard for the comparison of the other batches because it was approved in the bioequivalence test.

\section{Tablet characterization}

\section{Tablet evaluation according to pharmacopoeic tests}

Average weight tests, hardness, friability, disintegration time, assay and humidity followed the recommendations in the Brazilian Pharmacopoeia $5^{\text {th }}$ edition (Farmacopeia Brasileira, 2010).

\section{Dissolution profile}

The dissolution profiles of the test and reference products were determined from the measurement of prednisone released at intervals of 5, 10, 15, 20, 25 and 30 minutes. The apparatus 2 (paddle) was used with a stirring rate of $50 \mathrm{rpm}$. The dissolution medium used was $900 \mathrm{~mL}$ of distilled water at $37^{\circ} \mathrm{C}$. The volume collected was 15 $\mathrm{mL}$ without replacement from 6 vessels, and each batch was read by UV-Vis at $242 \mathrm{~nm}$. An SR8 PLUS Hanson Research dissolutor was used. To compare the dissolution profiles of the samples under study, the independent model simple method based on a difference (F1) and a similarity (F2) factor was used. 
TABLE I - Excipients present in the reference medicine and pilot batches

\begin{tabular}{lcc}
\hline Excipients & R023 & Test batches \\
\hline Starch (corn) & $\mathrm{X}$ & $\mathrm{X}$ \\
Croscarmellose sodium & $\mathrm{X}$ & \\
Magnesium stearate & $\mathrm{X}$ & $\mathrm{X}$ \\
Sodium starch glycolate & & $\mathrm{X}$ \\
Lactose monohydrate & $\mathrm{X}$ & \\
Sodium lauryl sulfate & & $\mathrm{X}$ \\
Mannitol & & $\mathrm{X}$ \\
Povidone (PVP) & $\mathrm{X}$ & $\mathrm{X}$ \\
Magnesium silicate & & $\mathrm{X}$ \\
\hline
\end{tabular}

All batches were packaged in PVC blisters, as informed by the reference product manufacturer.

\section{Stability study}

Samples from all batches were stored in a controlled climate room with a temperature of $30{ }^{\circ} \mathrm{C} \pm 2{ }^{\circ} \mathrm{C}$ and a relative humidity $(\mathrm{RH})$ of $75 \% \pm 5 \%$. Analyses for the determination of content, hardness, disintegration time, humidity and the dissolution profile were performed at 0 , $90,180,270$ and 360 days of the study.

\section{RESULTS AND DISCUSSION}

\section{Prednisone API characterization}

\section{Thermogravimetric analysis (TGA)}

From the TG curves (Figure 1) obtained for samples $\mathrm{A}$ and $\mathrm{B}$, at zero and 360 days, both samples were thermally stable up to approximately $261{ }^{\circ} \mathrm{C}$. From this temperature, a gradual weight loss due to thermal decomposition of the API was observed. This result excludes the possibility of said samples when treating the monohydrate form or solvate with chloroform, as reported in the literature, because the samples studied exhibited no mass loss until the beginning of their thermal decomposition (KuhnertBramdstätter, Gasser, 1971; Mesley, Johnson, 1965).

\section{Differential scanning calorimetry (DSC)}

The calorimetric profiles presented in Figure 2 indicate the possibility that two different crystalline forms exist because the melting peaks displayed different temperatures. The results of the tests at 2.5 and $5{ }^{\circ} \mathrm{C} / \mathrm{min}$ are not presented here, but they were identical to those obtained at $10^{\circ} \mathrm{C} / \mathrm{min}$.

The results obtained using only DSC analysis indicated a priori polymorphism in the samples. These data however contradict those obtained by X-ray diffraction.
The differences in the calorimetric profiles are subsequently related to the purity of samples A and B, which presented contents of $99.7 \%$ and $98.5 \%$, respectively. The presence of small amounts of impurities in a substance may decrease the melting point and increase its melting range (Donnelly et al., 1990). In the literature, authors have also used DSC to determine the purity of a given substance (Ferguson et al., 2000; Schnitzler et al., 2001). However, this technique should not be used for this purpose when the analyte decomposes during its fusion (Dooren, Muller, 1984), such as for prednisone (Farmacopeia Brasileira, 2010). Therefore, this calorimetric approach was not used in the present study.

\section{Powder X-ray diffraction}

Despite the question raised by DSC regarding the presence of polymorphism in the samples, characterization by X-ray diffraction (Figure 3 ) confirmed the presence of the same crystalline phase in samples A and $\mathrm{B}$. The peaks in the diffraction pattern are the same in both samples. At both the initial and final stability study times, there were no differences in the $2 \theta$ peak positions. The study also demonstrated that compared with an XRD pattern simulated from crystallographic data of an anhydrous crystalline form of prednisone deposited in the CSD (Allen, 2002), the samples had the same crystalline phase as that described here. Therefore, it is concluded that during the study period and at the temperature and relative humidity conditions used for storage, no crystalline phase transition was observed in the samples.

\section{Infrared spectroscopy}

The infrared absorption spectrum results demonstrated that at time zero, prednisone samples A and $\mathrm{B}$ alone exhibited absorption maxima at the same wavelength and the same relative intensities as those observed in the spectrum of samples of the USP and Brazilian Pharmacopoeia standards (Figure 4). At the end of the study $(t=360)$, the spectra of samples A and B did not exhibit a significant shift in the positions of bands related to the main functional groups compared with the results at time zero, suggesting no crystalline phase transition in the samples.

\section{Intrinsic dissolution}

The intrinsic dissolution rate (IDR) is an important tool to evaluate the differences between polymorphs and solvates, particularly when there is a small amount of sample available (Qiu, Chen, Zhang, 2009). This type of dissolution evaluates the API in an isolated form, i.e., 

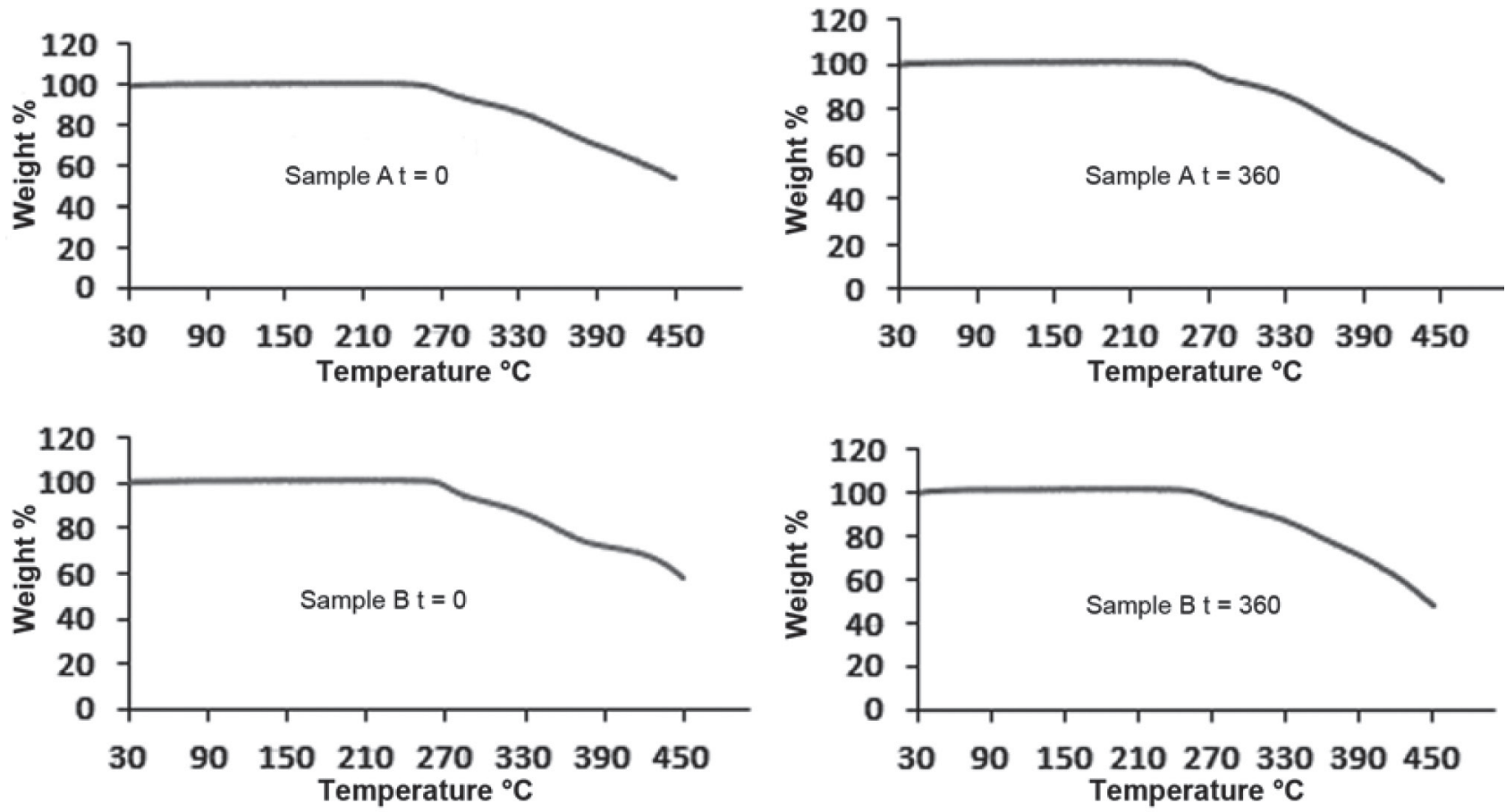

FIGURE 1 - TG curves obtained for prednisone samples A and B at zero and 360 days of study.

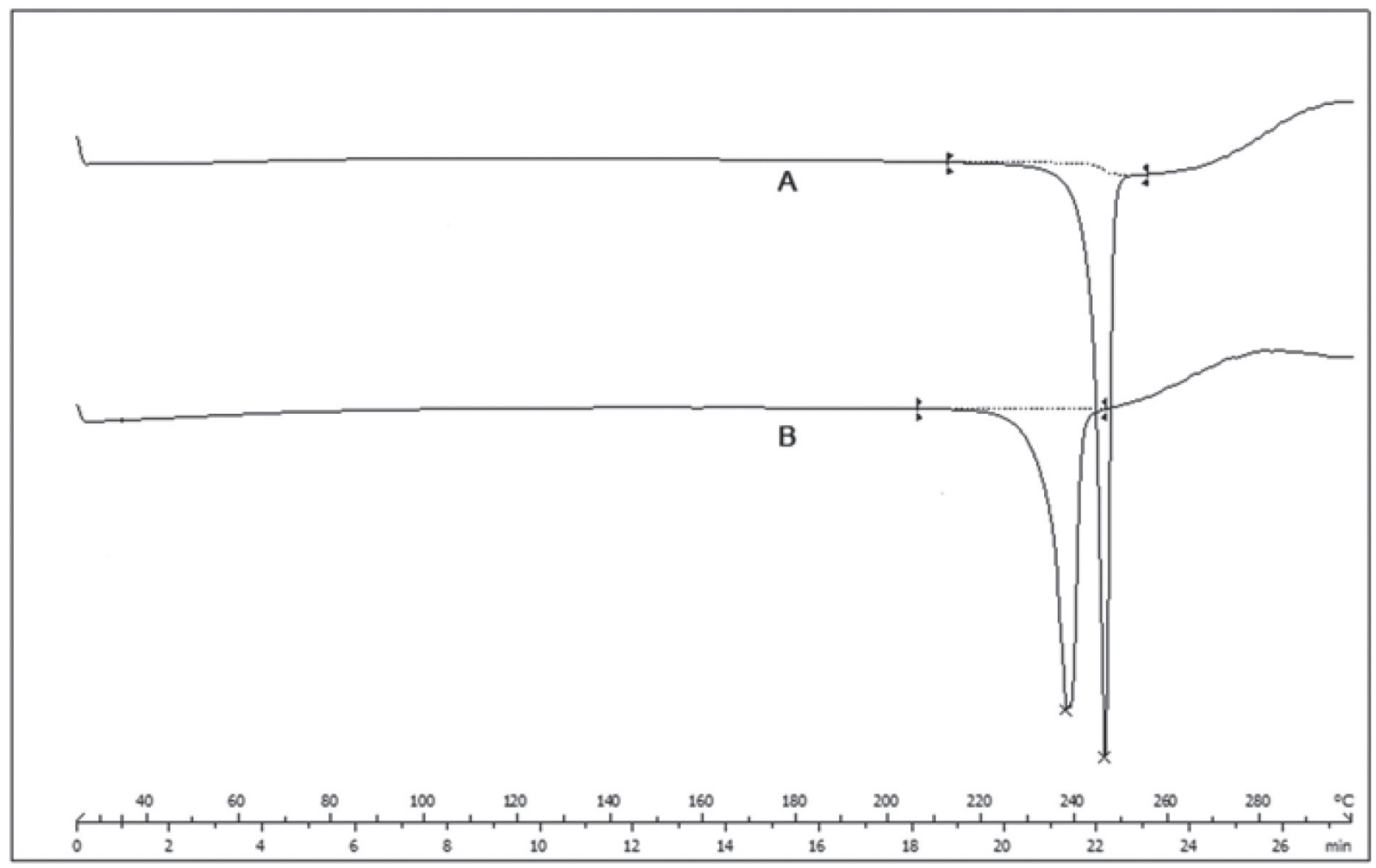

FIGURE 2 - DSC curves of samples A and $\mathrm{B}$ at a heating rate of $10^{\circ} \mathrm{C} / \mathrm{min}$.

without the presence of excipients (Gibson, 2009). The IDR of a drug is expressed in $\mathrm{mg} / \mathrm{min} / \mathrm{cm}^{2}$, and its value is obtained by dividing the angular coefficient obtained from the straight dissolution equation by the surface area of the compact formed by the drug. The results obtained for samples A and B are presented in Figure 5. 


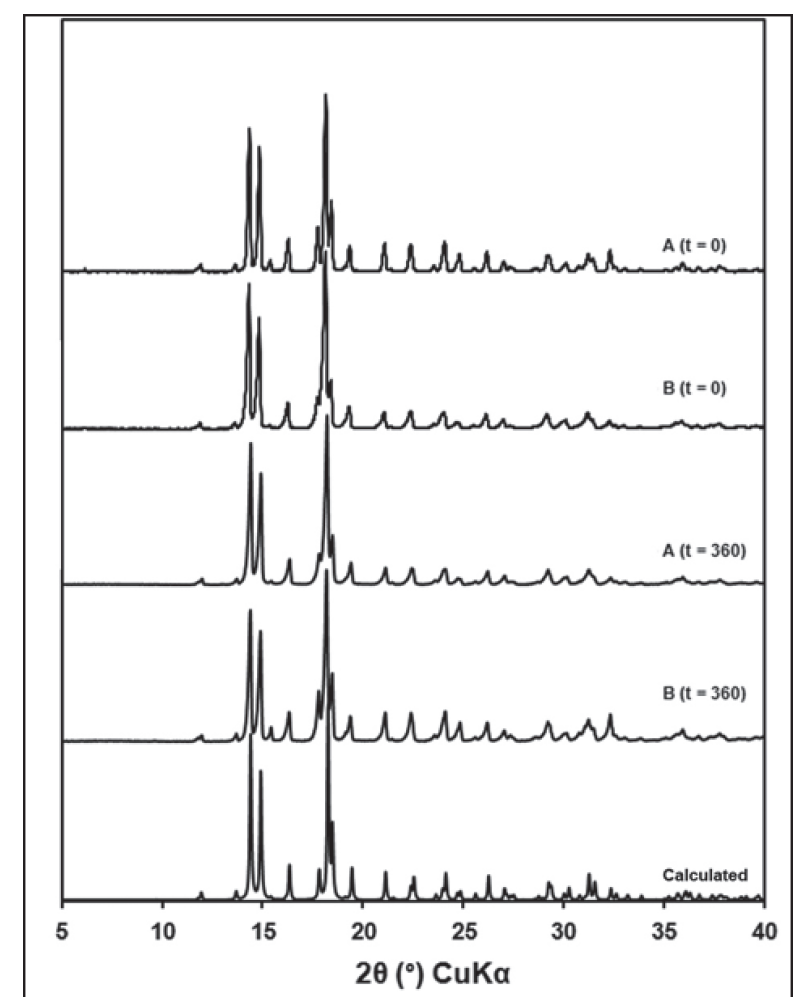

FIGURE 3 - Diffraction patterns of prednisone samples A and $\mathrm{B}$ at zero and 360 days of the stability study and the simulated pattern.
As shown in Figure 5, the intrinsic dissolution profiles revealed a pronounced linear behaviour because both samples had a coefficient of determination that was greater than 0.99 . With this linearity, it was concluded that there was no phase transition during the analysis and that the sink condition was also maintained during all times considered in the analysis.

Samples A $\left(6.71 \mathrm{mg} / \mathrm{min} / \mathrm{cm}^{2}\right)$ and B $(6.73 \mathrm{mg} /$ $\mathrm{min} / \mathrm{cm}^{2}$ ) exhibited similar dissolution profiles and IDR. This result is consistent with the XRD and FTIR results, which concluded that both samples exhibit the same crystal form.

Similar to the results obtained in the solubility test to classify the samples as highly soluble according to the BCS, a study correlating the IDR of 15 drugs performed by $\mathrm{Yu}$ et al. (2004) considered that an IDR greater than $0.1 \mathrm{mg} \cdot \mathrm{min}^{-1} . \mathrm{cm}^{-2}$ indicates high solubility, and drugs with lower values exhibit low solubility. Thus, according to this study, both samples are classified as highly soluble. Zakeri-Milani et al. (2009) mentioned approximately 0.58 , 0.63 , and $3.45 \mathrm{mg} / \mathrm{min} / \mathrm{cm}^{2}$ for furosemide (solubility of $1.474 \mathrm{mg} / \mathrm{mL})$, ketoprofen $(2.12 \mathrm{mg} / \mathrm{mL})$, and atenolol $(16.87 \mathrm{mg} / \mathrm{mL})$, respectively. Dezani et al. (2013) reported that the zidovudine (solubility of $\sim 20 \mathrm{mg} / \mathrm{mL}$ ) IDR is $0.75 \mathrm{mg} / \mathrm{min} / \mathrm{cm}^{2}$.
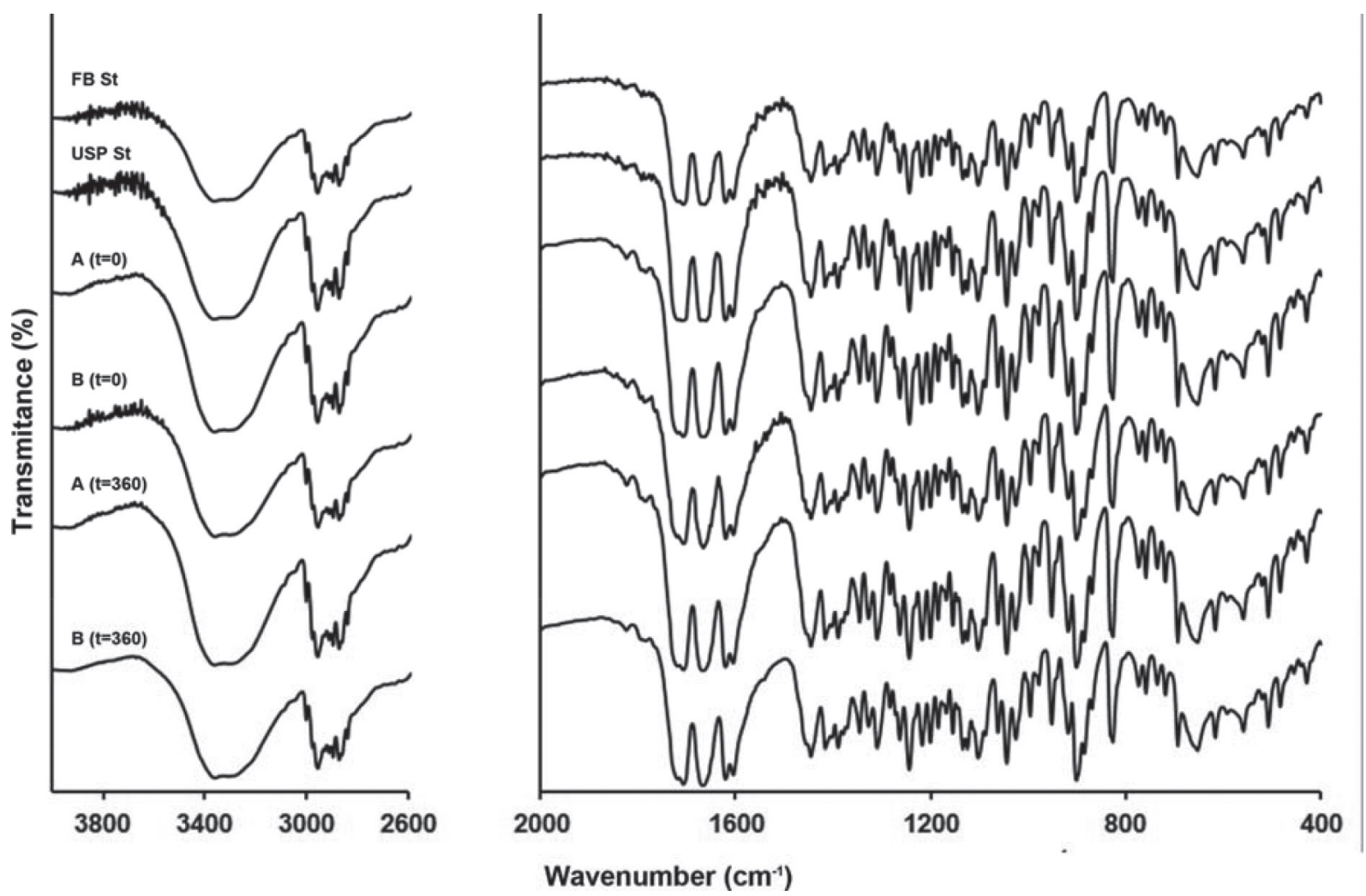

FIGURE 4 - Fourier transform infrared spectroscopy (FTIR) of prednisone samples A and B at zero and 360 days of the stability study and the USP (USP St) and Brazilian Pharmacopoeia (FB St) standards. 


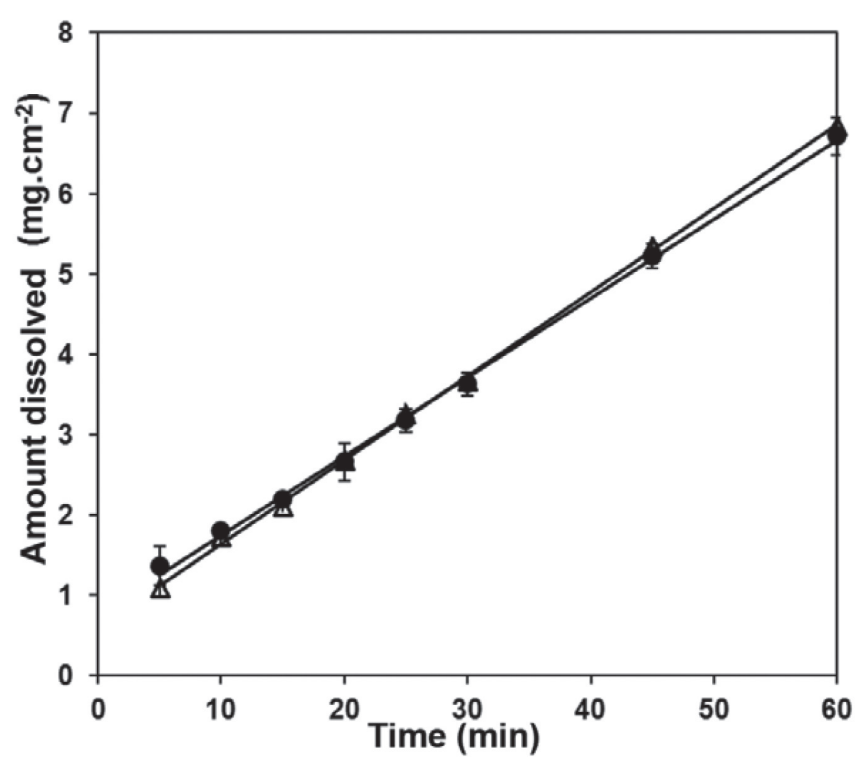

FIGURE 5 - Intrinsic dissolution of prednisone samples A and B in $900 \mathrm{~mL}$ of water containing $1.2 \%$ sodium lauryl sulfate using apparatus 2 at $150 \mathrm{rpm}$.

\section{Powder dissolution}

The results of the powder dissolution for both samples are presented in Figure 6. Samples A and B had a mean dissolution of $87.7 \%$ and $85.1 \%$ at 30 minutes, respectively. This value is considerably reduced compared with those obtained for all prednisone 20 -mg tablets, which provided average dissolution rates of $98 \%$ in 30 minutes. This discrepancy in the results may have occurred during the analysis because part of the active drug floated on the surface of the medium and/or attached to the apparatus (paddle), forming a cluster. Therefore, part of the active added mass did not come into contact with the environment and did not undergo the dissolution process. This observation is not so common in tablet dissolution because the excipients in this case can enhance powder wettability and lower static properties verified in the powder alone.

Importantly, in addition to being a hydrophobic drug, the analysed prednisone samples exhibit a very small particle size $(99 \%<30 \mu \mathrm{m})$, which leads to aggregation of the particles, reducing the dissolution rate.

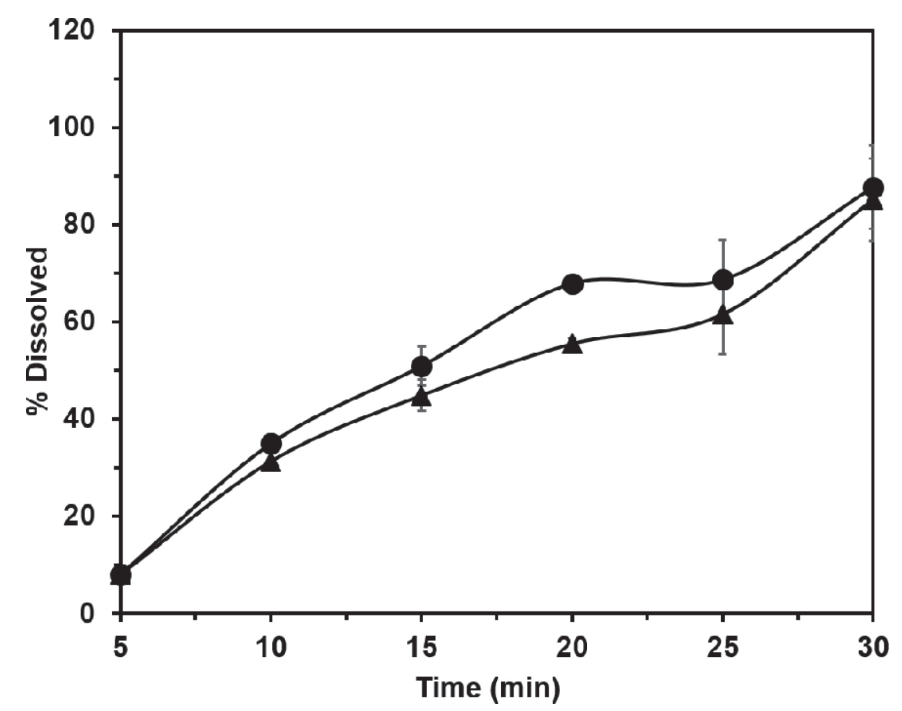

FIGURE 6 - Comparison between powder dissolution profiles of prednisone samples A (circle) and B (triangle).

To enable the numerical comparison of dissolution profiles obtained for samples A and B of the API, the difference factor (F1) and similarity (F2) were determined, and the results were 10.03 and 58.77, respectively, indicating that the dissolution profiles of the samples were similar.

\section{Solubility (saturation)}

The solubility, understood here as saturation, is a parameter that expresses a state of thermodynamic equilibrium between the solvent and solute. This equilibrium is dependent on a number of experimental conditions, such as temperature (Qiu, Chen, Zhang, 2009). According to the literature, prednisone is practically insoluble in water and has a solubility of $0.133 \mathrm{mg} / \mathrm{mL}$ at $25^{\circ} \mathrm{C}$ (Vogt et al., 2007).

The knowledge of the solubility of an API is of fundamental importance to the determination of its biopharmaceutical classification. In accordance with the BCS, the solubility should be determined at $37^{\circ} \mathrm{C}$ and in an aqueous medium with different $\mathrm{pH}$ values. Table II presents the solubility values experimentally obtained according to the BCS for prednisone samples A and B.

TABLE II - Solubility values experimentally obtained according to the BCS for prednisone samples A and B

\begin{tabular}{lcccc}
\hline \multirow{2}{*}{ Media } & \multicolumn{2}{c}{ Solubility $(\mathbf{m g} / \mathbf{m L})$ at $\mathbf{3 7} \mathbf{~}^{\mathbf{C}}$} & \multicolumn{2}{c}{ Volume $(\mathbf{m L})$ necessary to solubilize 50 $\mathbf{~ m g}$} \\
\cline { 2 - 5 } & Sample A & Sample B & Sample A & Sample B \\
\hline HCl buffer, pH 1.2 & 4.48 & 4.51 & 11.03 & 11.08 \\
Water, pH 5.5 & 4.53 & 4.54 & 11.04 & 11.01 \\
Phosphate buffer, pH 6.8 & 4.55 & 4.57 & 10.98 & 10.94 \\
\hline
\end{tabular}


Samples A and B exhibited a solubility of approximately $4.5 \mathrm{mg} / \mathrm{mL}$ at $37^{\circ} \mathrm{C}$ for all tested $\mathrm{pH}$ values. This result is consistent with the information obtained from the literature that ranks prednisone as a neutral molecule; therefore, changes in $\mathrm{pH}$ do not affect its solubility (Vogt et al., 2007).

Based on these results, both samples can be classified as highly soluble, and the volume of medium required to dissolve $50 \mathrm{mg}$ of prednisone (a larger dose available for domestic dosage) was approximately $11 \mathrm{~mL}$ at all $\mathrm{pH}$ values tested, which is significantly less than the $250 \mathrm{~mL}$ recommended by the BCS.

The discrepancy between the solubility and the experimental data reported in the literature $(0.133 \mathrm{mg} /$ $\mathrm{mL}$ ) may be related to the different temperatures at which the solubility was determined because prednisone exhibits endothermic properties, i.e., its solubility increases with increasing temperature (Vogt et al., 2007).

\section{Scanning electron microscopy}

The photomicrographs obtained for both samples A and B (Figure 7) reveal irregular and small particles that are mostly smaller than 30 micrometres. Note that
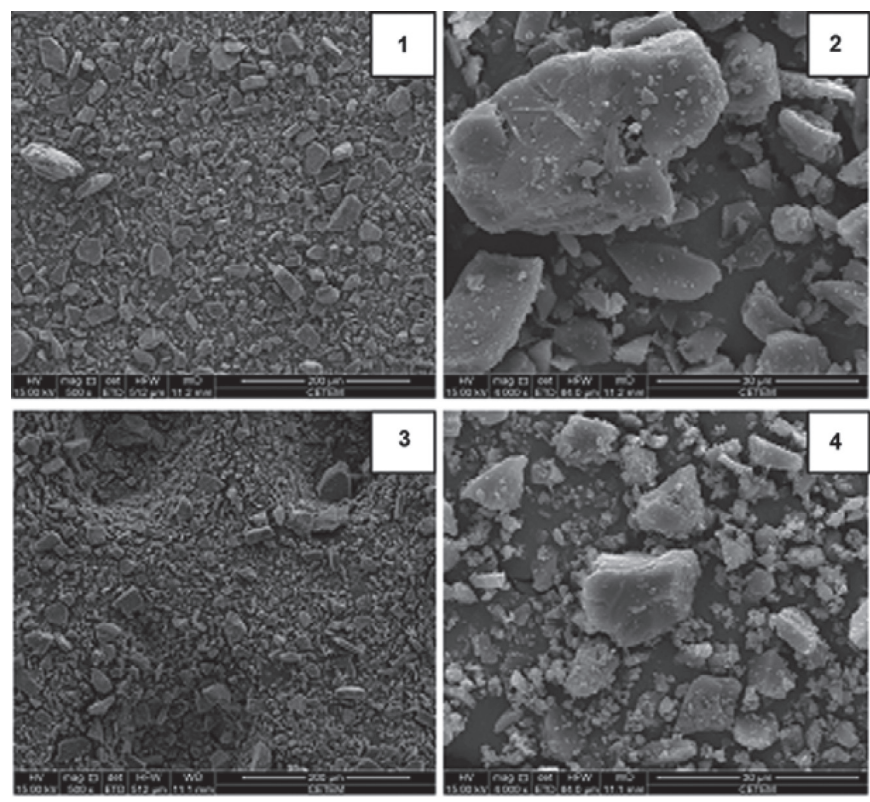

FIGURE 7 - SEM photomicrographs of sample A (1 and 2) and sample B (3 and 4). these data are consistent with the results $(99 \% \leq 30 \mathrm{mM})$ obtained by laser diffraction provided on the certificate of analysis (CoA) of the samples supplied by the manufacturers of both samples.

\section{Active pharmaceutical ingredient evaluation using pharmacopeic criteria}

Samples A and B were approved in all pharmacopeial tests. The contents found for the raw materials $\mathrm{A}$ and $\mathrm{B}$ at different time intervals are presented in Table III.

The contents of both samples showed no significant variation over the entire course of the study.

\section{Evaluation of prednisone tablets}

It is important to evaluate some basic physicochemical parameters of the tablets in addition to stability. During the development of drug products, quality control of the dosage forms must be evaluated from a variety of different aspects (Table IV).

According to the limits recommended by the Brazilian Pharmacopoeia $5^{\text {th }}$ edition to assess weight change in uncoated tablets, all samples were within the established limit. Notably, in general, all lots had a small increase in average weight and values for the maximum and minimum weights observed. This finding may be related to the small increase in moisture that occurred in all lots during the stability study.

Regarding disintegration, lots P0020020910, MEST01 and MEST02, which were produced with the same formulation, presented maximum values of 3 minutes and 20 seconds.

Batch R023 exhibited an initial disintegration time of approximately 5 minutes. That time underwent a change after $\mathrm{T}=180$ to 12 minutes and remained constant until the end of the study. This increase may be related to the excipient povidone present in the formulation, as this polymer can form a film on particles of the granulate and consequently the induration of the tablets over time, thereby jeopardizing the process of disintegration and dissolution (Blok, 2007; Murthy, Guebre-Sellassie, 1993).

The Brazilian Pharmacopoeia $5^{\text {th }}$ edition does not recommend tests for moisture in prednisone tablets, but

TABLE III - Assay results (\%) of samples A and B at 0, 90, 180, 270 and 360 days of the stability study

\begin{tabular}{lccccc}
\hline Samples & Time zero & 90 days & 180 days & 270 days & 360 days \\
\hline A & 99.7 & 99.8 & 99.6 & 99.8 & 99.6 \\
B & 98.5 & 98.8 & 98.7 & 98.6 & 98.6 \\
\hline
\end{tabular}


TABLE IV - Compilation of the results of pharmacopoeic parameters of the formulations evaluated during the stability study

\begin{tabular}{|c|c|c|c|c|}
\hline \multirow{2}{*}{ Parameter } & \multicolumn{4}{|c|}{ Result } \\
\hline & R023 & P0020020910 & MEST01 & MEST02 \\
\hline \multicolumn{5}{|c|}{ Average weight (mg) } \\
\hline $\mathrm{T}=0$ & 303.4 & 142.1 & 143.2 & 140.7 \\
\hline 90 days & 303.7 & 142.3 & 143.4 & 140.9 \\
\hline 180 days & 303.6 & 143.1 & 143.6 & 141.2 \\
\hline 270 days & 304.1 & 143.0 & 143.7 & 141.3 \\
\hline 360 days & 304.3 & 143.4 & 144.0 & 141.2 \\
\hline \multicolumn{5}{|c|}{ Disintegration (specification $<30 \mathrm{~min}$ ) } \\
\hline $\mathrm{T}=0$ & $5 \min 27 \mathrm{~s}$ & $2 \min 38 s$ & $2 \min 16 s$ & $2 \min 26 s$ \\
\hline 90 days & $5 \min 50 \mathrm{~s}$ & $2 \min 20 s$ & $2 \min 22 \mathrm{~s}$ & $2 \min 34 \mathrm{~s}$ \\
\hline 180 days & $12 \min 12 \mathrm{~s}$ & $2 \min 50 s$ & $2 \min 58 \mathrm{~s}$ & $2 \min 40 s$ \\
\hline 270 days & $12 \min 47 \mathrm{~s}$ & $2 \min 44 s$ & $2 \min 15 s$ & $2 \min 05 \mathrm{~s}$ \\
\hline 360 days & $12 \mathrm{~min} 20 \mathrm{~s}$ & $3 \min 20 s$ & $3 \min 05 s$ & $3 \min 20 s$ \\
\hline \multicolumn{5}{|c|}{ Humidity content (\%) } \\
\hline $\mathrm{T}=0$ & 2.53 & 5.71 & 4.71 & 4.67 \\
\hline 90 days & 2.62 & 5.85 & 4.78 & 4.70 \\
\hline 180 days & 2.75 & 6.26 & 4.65 & 4.73 \\
\hline 270 days & 2.68 & 6.32 & 4.77 & 4.87 \\
\hline 360 days & 3.23 & 6.25 & 5.20 & 4.96 \\
\hline \multicolumn{5}{|c|}{ Hardness (N) (average \pm RSD) } \\
\hline $\mathrm{T}=0$ & $57.4 \pm 8.7$ & $53.1 \pm 8.1$ & $21.6 \pm 6.1$ & $33.0 \pm 6.5$ \\
\hline 90 days & $60.5 \pm 5.1$ & $55.6 \pm 10.5$ & $23.4 \pm 10.7$ & $33.6 \pm 11.3$ \\
\hline 180 days & $64.9 \pm 9.5$ & $56.8 \pm 5.6$ & $23.9 \pm 5.9$ & $35.5 \pm 6.7$ \\
\hline 270 days & $65.8 \pm 5.6$ & $56.2 \pm 7.5$ & $25.2 \pm 7.4$ & $38.5 \pm 5.9$ \\
\hline 360 days & $66.4 \pm 6.8$ & $55.8 \pm 5.7$ & $25.7 \pm 5.6$ & $38.7 \pm 7.3$ \\
\hline \multicolumn{5}{|c|}{ Friability (specification $<1 \%$ ) } \\
\hline $\mathrm{T}=0$ & 0.42 & 0.33 & 0.72 & 0.58 \\
\hline 90 days & NR & 0.36 & 0.67 & 0.43 \\
\hline 180 days & NR & 0.29 & 0.54 & 0.49 \\
\hline 270 days & NR & 0.25 & 0.45 & 0.33 \\
\hline 360 days & NR & 0.21 & 0.20 & 0.24 \\
\hline \multicolumn{5}{|c|}{ Assay (specification 90-110\%) (average \pm RSD) } \\
\hline $\mathrm{T}=0$ & $106.7 \pm 0.3$ & $100.6 \pm 0.4$ & $100.4 \pm 0.4$ & $101.7 \pm 0.2$ \\
\hline 90 days & $106.0 \pm 0.2$ & $100.4 \pm 0.2$ & $100.0 \pm 0.9$ & $101.2 \pm 0.3$ \\
\hline 180 days & $105.9 \pm 0.5$ & $100.1 \pm 0.4$ & $100.7 \pm 0.2$ & $101.3 \pm 0.3$ \\
\hline 270 days & $105.7 \pm 0.3$ & $100.2 \pm 0.7$ & $100.3 \pm 8.4$ & $100.7 \pm 0.5$ \\
\hline 360 days & $105.8 \pm 0.3$ & $99.9 \pm 0.2$ & $100.1 \pm 0.7$ & $100.4 \pm 0.2$ \\
\hline
\end{tabular}

$\mathrm{NR}=$ not realised

this parameter was evaluated during stability studies to assess a possible correlation with the mechanical strength test and the dissolution profile of the tablets studied because these data directly affect these parameters (Aulton, 2005). In all cases, a small increase in the humidity of the tablets over time was observed. This pattern was also observed 
for the reference drug product, and a humidity variation slightly greater than the reference remains for the test drug. For a PVC, i.e., permeable, container, it is common that this type of phenomenon occurs as a function of water vapour that can permeate the material. Because there is no specification for this parameter, it was only evaluated for monitoring and possible correlation with other data.

According to the Brazilian Pharmacopoeia, the hardness test is informative but does have existing approval parameters (Farmacopeia Brasileira, 2010). Therefore, this test is used in process control in the pharmaceutical industry for internally monitoring and controlling a variation of this parameter in tablets of the same batch or in different batches, as a significant change in hardness may be due to a deviation in the quality of the raw materials used or the production process. However, the mechanical strength of the tablets can also be altered during storage. Such changes can be caused by numerous factors, including moisture absorption, changes in crystal structure and plastic deformation of particles (Aulton, 2005).

The results obtained during the stability study indicate a small increase in hardness for all batches. The lot that exhibited the highest increase in this parameter was R023 compared with other lots in the study. Similar to disintegration, the increase in hardness was potentially triggered by the association of factors, such as increased moisture absorption and the use of povidone in the tablets
(Blok, 2007; Murthy, Guebre-Sellassie, 1993).

The friability results reveal an increase in the mechanical resistance to attrition of the tablets during the stability study, which may be associated with the moisture absorbed by the tablets. This moisture would lead to the formation of solid bridges between particles, increasing their resistance (Aulton, 2005). Importantly, the friability for the R023 batch was not assessed at all study times due to the unavailability of that lot on the market, but it has no impact on the statements presented here.

All results of content and uniformity of content are approved. However, a certain strangeness was noted in the content values for the reference product. Despite falling in the range of approval, these values are well above average, tending towards the upper range limit. This type of result suggests that one cannot categorically state that there is an addition of excess active ingredient during manufacturing, a practice known as overage, which is not recommended by regulators. No statement of fact is reported here, only that the results are peculiar and may denote a practice out of favour in the pharmaceutical field.

\section{Dissolution profiles of the tablets}

The individual results of the dissolution profiles of lots R023, P0020020910, MEST01, and MEST02 at zero, 90, 180, 270 and 360 days of the stability study are presented in Figure 8.

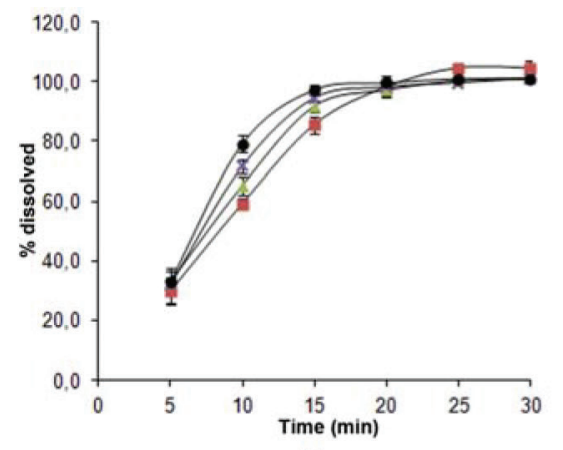

(a)

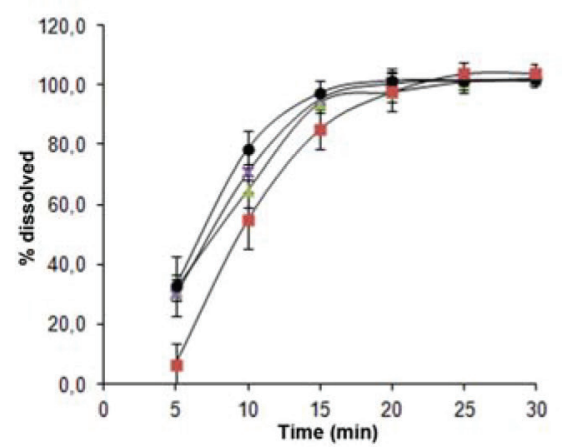

(d)

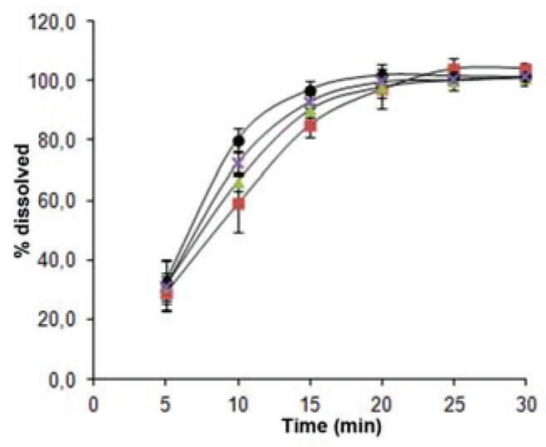

(b)

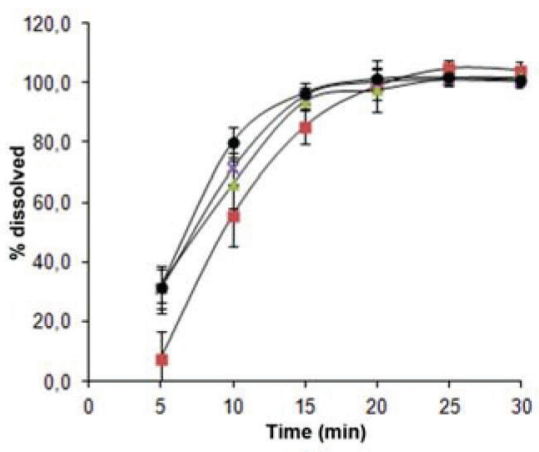

(c)

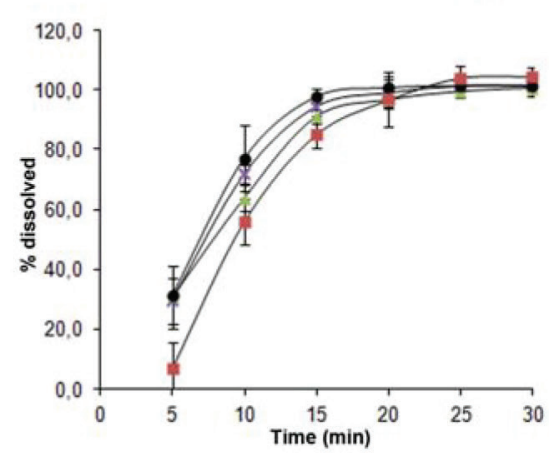

(e)

FIGURE 8 - Dissolution profiles of prednisone tablets for batches R023(•), P0020020910 (•), MEST01 ( $\mathbf{\Delta})$, and MEST02 (x) at times (a) 0, (b) 90, (c) 180, (d) 270 and (e) 360 days. 
The F1 and F2 values, comparative indices used for the evaluation of the similarity and difference between two dissolution profiles were also calculated to better verify the monitoring of lots for stability. The results are presented in Table V.

Batch P0020020910 exhibited an average release rate that was greater than $85 \%$ within 15 minutes for all time points in the stability profile, which was maintained during the entire study. Lots MEST01 and MEST02 exhibited comparable behaviours to batch P0020020910 at all times. Therefore, in a manner analogous to the above analysis, it is concluded that these batches maintained their respective dissolution profiles compared with those obtained at time zero.

Although batch R023 presented an average release rate exceeding $85 \%$ within 15 minutes and values less than 15 for $\mathrm{F} 1$ and greater than 50 for $\mathrm{F} 2$ at all times of the stability study, the results presented in Table 5 and Figure 24 indicate that this batch underwent a significant change in its dissolution profile. This change began at $\mathrm{t}=180$ and remained at $\mathrm{t}=270$ and $\mathrm{t}=360$, when an active release within five minutes of $7.5 \%, 6.6 \%$ and $6.7 \%$, respectively, was observed. These values differ from the percentage release rates observed at time $\mathrm{t}=0$ and $\mathrm{t}=90$, which were $29.9 \%$ and $28.8 \%$, respectively, within five minutes. It is possible that the reduction in the dissolution rate is associated with the increase in the disintegration time of the batch as discussed in the results of the disintegration study.

Comparison of dissolution profiles is a useful tool when the behaviour of two drugs must be known before conducting a study of relative bioavailability/ bioequivalence or pharmaceutical equivalence to claim exemption from such studies or for a possible postregistration change (Anvisa, 2011; 2010). However, when performed during the stability study, this comparison enables the evaluation of whether a formulation that has an initial dissolution profile equivalent to another formulation maintains that status throughout its shelf life.

Importantly, the rate at which a drug is released from its dosage form can be a limiting factor in the rate of absorption. Thus, a possible variation in this parameter during storage can cause a change in the beginning intensity or duration of a therapeutic response (Murthy, Guebre-Sellassie, 1993).

All batches of $20-\mathrm{mg}$ prednisone tablets submitted to the study met the acceptance criteria established in the official monograph (Farmacopeia Brasileira, 2010), which must have a dissolution rate greater than $80 \%$ after 30 minutes of the test. According to the current Brazilian regulatory perspective, it is not necessary to calculate factor F1 or F2 for drugs of high solubility and rapid dissolution formulations. Therefore, batches P0020020910, MEST01 and MEST02 maintained their dissolution profiles equivalent to that of batch of $\mathrm{R} 023$ because these batches exhibited a dissolution that was greater than $85 \%$ for the first 15 minutes (Anvisa, 2010). However, during the study period, the F1 and F2 values calculated for lots P0020020910, MEST01 and MEST02 (Table V) showed a reduction of similarity and an increase in the difference between their dissolution profiles compared with batch $\mathrm{R} 023$. Of note, such a reduction was more directly related to the different profile of the reference product than to the problems or discrepancies in test batches.

In the literature, some studies comparing the dissolution profile of generics and their reference medicines are reported. Operto and collaborators (2008) compared 10 brands of paracetamol tablets produced in Argentina. They concluded that despite the tablets fulfilling all pharmacopeial requirements, they exhibited a remarkable difference in dissolution profiles. Kohler et al. (2009) evaluated the dissolution profiles of five generic $500 \mathrm{mg}$ dipyrone tablets and concluded that none were equivalent to the reference drug product.

Similarly, Brum et al. (2012) analysed 8 brands of 750-mg paracetamol tablets available in Brazil and also found that one of the generic brands did not show a dissolution profile equivalent to that of the reference product. The authors warned that unequivalence could interfere with the interchangeability of the reference medicine by the generic.

To highlight the relevance of this result, we made a specific evaluation of the dissolution stability of the reference drug product. Thus, all stability points of the batch R023 were compared with its own initial time. This type of evaluation has been reported by Murthy and Guebre-Sellassie (1993) as an important tool to predict the performance of a tablet during stability and to demonstrate whether it retains the same quality during the shelf-life. Most regulatory recommendations (as in Brazil) exclusively claim the dissolution results for registration but not the dissolution profile.

As noted in Table V, based on F1 and F2 values, the reference medicine was stable during the first year of the stability study. However, F2 was reduced from 95.99 at 90 days to 50.79 in one year, which is at the borderline of the approval limit. In the next stability point, the drug would likely be disapproved. Given that the shelf-life declared in the package of the medicine is 2 years, it can be questioned whether a patient taking this product close to this time is actually consuming a medicine with assured quality and 
TABLE V - F1 and F2 factors for all of the batches compared with $\mathrm{R} 023$ at $\mathrm{t}=0, \mathrm{t}=90, \mathrm{t}=180, \mathrm{t}=270$ and $\mathrm{t}=360$ days of study

\begin{tabular}{lccccc}
\hline \multirow{2}{*}{ Days of study } & \multirow{2}{*}{ Factor } & \multicolumn{3}{c}{ Batches } \\
\cline { 3 - 6 } & & R023* & P0020020910 & MEST01 & MEST02 \\
\hline Beginning $(\mathrm{t}=0)$ & F1 & - & 9.02 & 4.84 & 6.65 \\
& F2 & - & 50.31 & 67.51 & 58.32 \\
\hline 90 & F1 & 0.97 & 9.87 & 4.52 & 7.49 \\
& F2 & 95.99 & 48.98 & 68.20 & 56.15 \\
\hline 180 & F1 & 5.72 & 15.01 & 11.12 & 12.79 \\
& F2 & 51.56 & 41.41 & 46.76 & 45.21 \\
\hline 360 & F1 & 6.09 & 15.58 & 10.57 & 12.60 \\
& F2 & 50.59 & 40.64 & 46.88 & 45.33 \\
\hline
\end{tabular}

* This batch was evaluated by comparing its own results during stability to $\mathrm{t}=0$.

clinical efficiency. Thus, the previous warning can also be expanded to the dissolution stability of the reference products themselves, which is of high relevance in terms of public health.

\section{CONCLUSION}

All techniques used in the characterization of prednisone samples A and B were helpful, providing information that indicated that both samples presented the same crystalline form and did not undergo transition over the stability study. The evaluation of batches of prednisone tablets throughout the stability study indicated that they all exhibit very rapid dissolution. Notably, when analysed individually, the dissolution profiles of all batches, except R023, exhibited minimal variation and remained similar during the entire study period. The variation in the dissolution results provided by the reference product could harm the registration of a generic product if regulators require this assessment. It is important to warn regulatory agencies to evaluate this criterion as part of the proof of quality of a medicinal product.

\section{REFERENCES}

Agência Nacional de Vigilância Sanitária. ANVISA. Instrução Normativa $\mathrm{n}^{\circ} .2$, de 14 de março de 2013. Determina a publicação da lista de fármacos candidatos à bioisenção baseada no sistema de classificação biofarmacêutica. Diário Oficial da União, 4 mar. 2013.
Agência Nacional de Vigilância Sanitária. ANVISA. Resolução $n^{\circ} .31$, de 11 de agosto de 2010. Requisitos para realização dos estudos de equivalência farmacêutica e de perfil de dissolução, a serem atendidos pelos centros de equivalência farmacêutica $\mathrm{e}$ patrocinador do estudo. Diário Oficial da União, 12 ago 2010.

Agência Nacional de Vigilância Sanitária (Brasil). ANVISA. Resolução $n^{\circ}$. 16, de 2 de Março de 2007. Registro de Medicamento Genérico. Diário Oficial da União, 5 ago. 2011.

Allen FH. The Cambridge structural database: a quarter of million crystal structures and rising. Acta Crystallogr, Sect B: Struct Sci. 2002;58(1):380-8.

Aulton ME. Delineamento de formas farmacêuticas. Porto Alegre: Artmed; 2005. 677 p.

Blok LC. Desenvolvimento e caracterização de comprimidos de metformina $500 \mathrm{mg}$ de liberação imediata: efeito de aglutinantes [mestrado]. Itajaí: Universidade do Vale do Itajaí; 2007.91 p.

Brum TF, Laporta LV, Junior FRP, Gonçalves CA, Santos MR. Equivalência farmacêutica e estudo comparativo dos perfis de dissolução de medicamentos genéricos contendo paracetamol. Rev Cienc Farm Basica Apl. 2012;33(3):373-8.

Dezani AB, Pereira TM, Caffaro AM, Reis JM, Serra CHR. Equilibrium solubility versus intrinsic dissolution: characterization of lamivudine, stavudine and zidovudine for BCS classification. Braz J Pharm Sci. 2013;49(4):853-63. 
Donnelly JR, Drewes LA, Johnson RL, Munslow WD, Knapp KK. Purity and heat of fusion data for environmental standards as determined by differential scanning calorimetry. Thermochim Acta. 1990;167(2):155-87.

Dooren AA, Miiller BW. Purity determinations of drugs with differential scanning calorimetry (DSC): critical review. Int J Pharm. 1984;20(3):217-33.

European Pharmacopoeia. 6. ed. Council of Europe:Strasbourg; 2010 .

Farmacopeia Brasileira. 5. ed. São Paulo: Atheneu; 2010.

Ferguson HF, Frurip DJ, Pastor AJ, Peerey LM, Whiting LF. A review of analytical applications of calorimetry. Thermochim Acta. 2000;363(1):1-21.

Fung KY, Ng KM. Product-centered processing: pharmaceutical tablets and capsules. AIChE J. 2003;49(5):1193-215.

Gibson M. Pharmaceutical Preformulation and Formulation. 2. ed. v.199. New York: Informa Healthcare USA; 2009. 541 p.

Iacocca RG, Burcham CL, Hilden LR. Particle engineering: A strategy for establishing drug substance physical property specifications during small molecule development. J Pharm Sci. 2010;99(1):51-75.

Kaiser H, Kley HK. Cortisontherapie: corticoide in klinik und praxis. 11. ed. Thieme: Stuttgart; 2002.

Kohler LF, Nascimento HD, Schwengber ELL, Bandeira ZMP, Pazin GV, Machado SRP. Avaliação biofarmacotécnica e perfil de dissolução de comprimidos de dipirona: equivalências farmacêutica entre medicamentos de referência, genéricos e similares. Rev Bras Farm. 2009;90(4):309-15.

Kuhnert-Bramdstätter M, Gasser P. Solvates and polymorphic modifications of steroid hormones. Microchem J. 1971;16(4):590-601.

Macrae CF, Bruno IJ, Chisholm JA, Edgington PR, Mccabe P, Pidcock E, Rodrigues-Monge L, Taylor R, Van de Streek J, Wood PA. New features for the visualization and investigation of crystal structures. J Appl Crystallogr. 2008;41:466-70.

Mesley RJ, Johnson CA. Infrared identification of pharmaceutically important steroids with particular reference to the occurrence of polymorphism. J Pharm Pharmacol. $1965 ; 17: 329-40$.
Murthy KS, Ghebre-Sellassie I. Current perspectives on the dissolution stability of solid oral dosage forms. J Pharm Sci. 1993;82(2):113-25.

Ochi M, Kimura K, Kanda A, Kawachi T, Matsuda A, Yuminoki K, Hashimoto N. Physicochemical and pharmacokinetic characterization of amorphous solid dispersion of meloxicam with enhanced dissolution property and storage stability. AAPS PharmSciTech. 2016;17(4):932-9.

Okumu A, Dimaso M, Löbenberg R. Computer simulations using GastroPlus ${ }^{\mathrm{TM}}$ to justify a biowaiver for etoricoxib solid oral drug products. Eur J Pharm Sci. 2009;72(1):91-8.

Operto MA, Castellano PM, Kaufman TS. Evaluacion y analisis de parametros de calidad de comprimidos de paracetamol. Lat Am J Pharm. 2008;27(4):603-7.

Passion P, Gouveia LF, Morais JAG. Prediction of the human oral bioavailability by using in vitro and in silico drug related parameters in a physiologically based absorption model. Int $\mathrm{J}$ Pharm. 2012;429(1-2):84-98.

Payghan SA, Kate VK, Purohit S, Bhandari A. Effect of aging conditions on the dissolution and diffusion stability of non aqueous emulsion. Inventi Rapid: Pharm Tech. 2012;3:1-7.

Qiu Y, Chen Y, Zhang GZ. Developing solid oral dosage forms: pharmaceutical theory and practice. London: Elservier; 2009. 907 p.

Romanholi DJPC, Salgado LR. Síndrome de cushing exógena e retirada de glicocorticóides. ABEM. 2007;51(8):1280-92.

Schnitzler E, Carvalho-Filho MAS, Stadler CC, Volpato AM, Ionashiro M. Aplicação da calorimetria exploratória diferencial (DSC) na caracterização térmica do acetato de dexametasona, excipientes e do creme de dexametasona. Eclética Quím. 2001;26:1-18.

Storpirtis S, Gonçalves JE, Chiann C, Gai MN. Biofarmacotécnica. Ganabara Koogan: Rio de Janeiro; 2009. $321 \mathrm{p}$.

United States Pharmacopeia. USP 35. Rockville: The United States Pharmacopeial Convention; 2012.

Vidal NLG, Brevedan MIV, Varillas MA, Simionato LD, Pizzorno MT. Effect of accelerated-aging conditions on the dissolution stability of ciprofloxacin tablets. Dissol Technol. 2010;Feb:23-29. 
Vogt M, Derendorf H, Krämer J, Junginger HE, Midha KK, Shah S, Dressman JB, Barends DM. biowaiver monographs for immediate release solid oral dosage forms: prednisone. J Pharm Sci. 2007;96(6):1480-9.

Wei H, Löbenberg R. Biorelevant dissolution media as a predictive tool for glyburide a class II drug. Eur J Pharm Sci. 2006;29(1):45-52.
Yu LX, Carlin AS, Amidon GL, Hussain AS. Feasibility studies of utilizing disk intrinsic dissolution rate to classify drugs. Int $\mathrm{J}$ Pharm. 2004;270(1-2):221-7.

Zakeri-Milani P, Barzegar-Jalali M, Azimi M, Valizadeh H. Biopharmaceutical classification of drugs using intrinsic dissolution rate (IDR) and rate intestinal permeability. Eur J Pharm Biopharm. 2009;73(1):102-6.

Received for publication on $29^{\text {th }}$ November 2016 Accepted for publication on $28^{\text {th }}$ March 2017 